\title{
Utilização de hidrocortisona em eqüinos submetidos a isquemia e reperfusão no jejuno e suas conseqüências sobre o cório laminar
}

[Hydrocortisone in horses submitted to jejunal isquemia and reperfusion and its effects in the laminar corium]

\author{
J.J.M. Rio Tinto ${ }^{1}$, G.E.S. Alves $^{2}$, R.R. Faleiros ${ }^{2}$, R.L. Santos ${ }^{2}$, A.P. Marques Júnior ${ }^{2}$, E.G. Melo ${ }^{2}$ \\ ${ }^{1}$ Centro de Estudos em Clínica e Cirurgia de Animais da PUC-MINAS/Betim \\ Rua do Rosário, 1600 \\ 32630-000 - Betim, MG \\ ${ }^{2}$ Escola de Veterinária da UFMG, Belo Horizonte, MG
}

\begin{abstract}
RESUMO
Estudou-se o efeito da administração de succinato sódico de hidrocortisona (SSH) no desenvolvimento de lesões no cório laminar de eqüinos. Doze animais foram submetidos à laparotomia sob anestesia geral e à isquemia total em dois segmentos do jejuno, enquanto três foram usados como controle. Após uma hora de isquemia, seis animais receberam $4,0 \mathrm{mg} / \mathrm{kg}$ de $\mathrm{SSH}$ por via intravenosa (grupo T) e seis receberam placebo (grupo NT). Após duas horas de isquemia foi restabelecido o fluxo de sangue local e, decorridas duas horas de reperfusão, foi realizada a laparorrafia e permitiu-se a recuperação anestésica. Após 12 horas do início da reperfusão, os animais foram sacrificados e deles colhidas amostras de tecido laminar para avaliação histomorfológica. As alterações avaliadas ao microscópio óptico foram quantificadas por escores que variaram de 0 a 3 . Os escores para lesão no tecido laminar foram semelhantes nos animais dos grupos T $(0,41)$ e NT $(0,54)$, permitindo concluir que a hidrocortisona não acentuou as lesões produzidas no tecido laminar após a isquemia e reperfusão no jejuno.
\end{abstract}

Palavras-chave: eqüino, laminite, reperfusão, isquemia, hidrocortisona

\begin{abstract}
To evaluate whether hydrocortisone sodium succinate (HSS) aggravates lesions in the laminar tissue secondary to intestinal ischemia and reperfusion (IR), two segments of the jejunum were isolated in 12 halothane-anesthetized horses, and total ischemia was induced on them. Three other horses were used as controls. One hour after the onset of the ischemia, HSS (4.0mg/ $/ \mathrm{kg})$ was administered intravenously to six animals (T group) and saline to the others (NT group). After two hours of ischemia and two hours of reperfusion the abdomen was closed and the horses were allowed to recover from anesthesia. After 12 hours of reperfusion the horses were euthanatized and biopsy specimens were taken from the laminar tissue and the lesions were evaluated and scored. No significant differences between $T$ (0.41) and NT (0.54) groups for laminar lesion scores were observed. The results indicate that HSS did not produce harmful effects in the laminar tissue, suggesting that the occurrence of undesirable effects in the digit are not a limiting factor for using this drug to treat equine patients with acute abdomen.
\end{abstract}

Keywords: equine, laminitis, reperfusion, ischemia, hydrocortisone

Recebido para publicação em 11 de março de 2003

Recebido para publicação, após modificações, em 15 de maio de 2004

E-mail: jorgeriotinto@hotmail.com 


\section{INTRODUÇÃO}

Os efeitos da isquemia e reperfusão (IR) têm sido intensamente estudados e considera-se que as doenças de origem isquêmica são a maior causa de óbito em humanos no ocidente (Forsyth e Guilford, 1995). Na medicina veterinária, as pesquisas sobre IR têm sido concentradas na área da gastroenterologia eqüina, na qual distúrbios acompanhados de isquemia são importantes pela elevada ocorrência (White, 1990a). Apesar dos recentes avanços na terapêutica e na clínica cirúrgica, a taxa de óbito em eqüinos portadores de enfermidades estrangulantes ainda é elevada, uma vez que a isquemia é particularmente grave no intestino e, até o momento, não se encontra disponível uma droga eficiente para o tratamento da lesão de reperfusão na rotina clínico-cirúrgica do abdome agudo em eqüinos (Hoogmoed e Snyder, 1997; Dabareiner et al., 1998).

Os glicocorticóides são uma alternativa para o tratamento das injúrias de IR no intestino de eqüinos, pois além de inibirem a fosfolipase $A_{2}$, também atenuam a infiltração leucocitária e as alterações vasculares verificadas no tecido pósisquêmico (Forsyth e Guilford, 1995). Sua eficiência foi demonstrada por Gaffin et al. (1986) em felinos e seu emprego foi sugerido por Moore et al. (1995).

A ocorrência de laminite, após distúrbios intestinais em eqüinos, foi considerada freqüente por Slater et al. (1995). Segundo Eyre et al. (1979) e May (1992), os glicocorticóides podem predispor ao desenvolvimento de lesão no tecido laminar em eqüinos. O succinato sódico de hidrocortisona (SSH) é um glicocorticóide de rápido início de ação e meia-vida biológica de menos de 12 horas (Behrend e Kemppainen, 1997).

O objetivo deste trabalho foi avaliar possíveis efeitos do succinato sódico de hidrocortisona nas lesões de isquemia e reperfusão no jejuno de eqüinos portadores de abdome agudo, bem como suas conseqüências sobre o cório laminar.

\section{MATERIAL E MÉTODOS}

O estudo foi realizado utilizando-se 15 eqüinos adultos, clinicamente sadios. Os animais foram vermifugados com moxidectin ${ }^{1}(0,4 \mathrm{mg} / \mathrm{kg})$ por via oral e permaneceram em piquete coletivo durante, no mínimo, uma semana antes do tratamento com SSH, onde receberam alimentação padronizada composta de feno de capim coast-cross, concentrado comercial e sal mineral. Doze animais foram distribuídos ao acaso em dois grupos experimentais, tratado (T) e não tratado (NT), cada um composto por três machos castrados e três fêmeas, com idade média de 7,8 $\pm 3,3$ anos para o $\mathrm{T}$ e $7,7 \pm 2,75$ anos para o $\mathrm{NT}$, peso médio de $290 \pm 41 \mathrm{~kg}$ para o $\mathrm{T}$ e $280 \pm 36 \mathrm{~kg}$ para o NT e escore corporal médio de 2,75 para o $\mathrm{T}$ e 2,58 para o NT. Outros três animais com escore corporal, peso e idade semelhantes, e que não foram submetidos a cirurgia, serviram como grupo-controle.

Os animais foram submetidos à anestesia geral inalatória com halotano ${ }^{2}$ e mantidos em decúbito dorsal para acesso ao intestino delgado. Durante a manutenção da anestesia foram fornecidos $10 \mathrm{ml} / \mathrm{kg} / \mathrm{min}$ de oxigênio e $10 \mathrm{ml} / \mathrm{kg} / \mathrm{h}$ de soro Ringer por via intravenosa (IV) e feita monitoração constante da pressão arterial pelo método direto (Hubbel, 1991) e da saturação da oxihemoglobina utilizando-se oximetria de pulso $^{3}$, sendo estabelecidos limites mínimos de $90 \%$ para a saturação da oxihemoglobina e de 70 $\mathrm{mmHg}$ para a pressão arterial média. Quando necessário, administrou-se etilefrina ${ }^{4}(0,2 \mathrm{mg} / \mathrm{kg}$ IV) para a elevação da pressão arterial e realizouse ventilação assistida ou controlada para a elevação da saturação da oxihemoglobina.

Os animais foram operados pela mesma equipe cirúrgica intercaladamente. Em cada animal foram demarcados no jejuno três segmentos. $\mathrm{O}$ primeiro animal foi submetido a isquemia durante duas horas, por meio da ligadura do tipo venosa de vasos mesentéricos. No segundo, a ligadura foi do tipo arteriovenosa. O terceiro segmento, que não sofreu isquemia, foi utilizado como controle. Uma hora após o início da isquemia os animais do grupo $\mathrm{T}$ receberam $4,0 \mathrm{mg} / \mathrm{kg} / \mathrm{IV}$ de succinato sódico de hidrocortisona $^{5}$ pela veia jugular, diluídos em

\footnotetext{
${ }^{1}$ Equest - Fort Dodge Saúde Animal.

${ }^{2}$ Halothano - Cristália Produtos Químicos e Farmacêuticos Ltda.

${ }^{3}$ Oxímetro de pulso Mod. 180 - Nellcor Puritan Bennett Inc.

${ }^{4}$ Cardioton - Boehringer De Angeli Química e

Farmacêutica/Divisão Vetmédica.

${ }^{5}$ Solu-Cortef 500mg - Rhodia Farma Ltda.
} 
$500 \mathrm{ml}$ de solução de $\mathrm{NaCl}$ a $0,9 \%$, administrado durante 10 minutos. Os do grupo NT receberam $500 \mathrm{ml}$ de solução de $\mathrm{NaCl}$ a $0,9 \%$ (placebo), administrados de modo semelhante à do grupo $\mathrm{T}$. Após duas horas de isquemia a circulação local foi restabelecida, iniciando-se a fase de reperfusão. Foram colhidas amostras dos três segmentos experimentais em intervalos de uma hora durante a fase de isquemia e até duas horas da fase de reperfusão, quando se realizou a laparorrafia e interrompeu-se a anestesia.

Após o término da cirurgia, os animais foram medicados com $0,1 \mathrm{mg} / \mathrm{kg}$ IV de tartarato de butorfanol e, ao deambularem, levados para baias individuais. Após quatro e oito horas do término da cirurgia receberam injeções adicionais de $0,1 \mathrm{mg} / \mathrm{kg}$ IV de butorfanol. Decorridas 12 horas do início da reperfusão, todos os eqüinos foram examinados para verificar a ocorrência de alterações nos dígitos e estimar a intensidade dos sintomas segundo a classificação de Obel (Moore et al., 1991). A seguir, 30 minutos após a eutanásia, foi colhida uma amostra de tecido laminar de cada membro torácico conforme descrito por Pollitt (1996).
As amostras de tecido laminar foram fixadas imediatamente após a colheita em formalina tamponada a $10 \%$, processadas pela técnica rotineira de inclusão em parafina e coradas pela hematoxilina e eosina e pelo ácido periódico de Schiff (Luna, 1968). De cada amostra foram obtidos dois cortes histológicos, codificados e avaliados ao microscópio óptico quanto às características histomorfológicas, sem que houvesse conhecimento de sua identificação por parte do examinador. Para a avaliação consideraram-se a extensão e a intensidade das lesões. O escore para a lesão, de cada animal, foi obtido pela média das lesões verificadas nas amostras colhidas nos membros direito e esquerdo. $O$ grau de lesão tecidual foi quantificado por meio de escores variando de 0 a 3, segundo método descrito por Pollitt (1996) (Tab. 1). Utilizaram-se valores intermediários quando houve dúvida quanto ao escore que melhor expressaria o grau de lesão presente nas amostras.

Os escores médios para lesão no tecido laminar de todos os eqüinos foram comparados utilizando-se o teste não paramétrico de KruskalWallis (Sampaio, 1998), considerando-se o nível de significância de $5 \%(\mathrm{P}<0,05)$.

Tabela 1. Caracterização do escore para lesão no tecido laminar nos membros torácicos de eqüinos segundo o método de coloração ${ }^{1}$

\begin{tabular}{lcc}
\hline Escore & Coloração & Lesão \\
\hline 0 & HE & Ausente \\
& PAS & Ausente
\end{tabular}

1 HE Presença de lesão apenas ao nível da base das LEP. Estreitamento das LES. Núcleos das células basais arredondados e próximos à MB. Difícil individualização das LES.

PAS Contorno das LES pouco nítido ou indistinto. Separação entre as células basais e a MB na extremidade das LES.

2 HE Presença de lesão apenas até o nível médio das LEP. Ausência de LDS entre as LES.

PAS Afastamento entre a extremidade da MB das LES e as LEP

3 HE Estreitamento ao nível da extremidade das LEP. Ao nível médio das LEP as LES formam uma massa amorfa de tecido entre as LEP e as LDP.

PAS Ausência de células basais ao nível da extremidade das LEP, restando apenas a MB das LES.

${ }^{1}$ Adaptado de Pollitt (1996). HE: hematoxilina e eosina. PAS: ácido periódico de Schiff. LEP: lâminas epidérmicas primárias. LES: lâminas epidérmicas secundárias. MB: membrana basal. LDS: lâminas dérmicas secundárias. LDP: lâminas dérmicas primárias.

\section{RESULTADOS E DISCUSSÃO}

Durante o período de permanência na baia, os eqüinos ficaram apáticos, porém em estação. Dois animais apresentaram dor abdominal discreta entre sete e oito horas do término da cirurgia, com remissão dos sinais de dor, 10 minutos após a administração de butorfanol, feita oito horas após o término da cirurgia.

Decorridas 12 horas do início da reperfusão, todos os eqüinos foram capazes de deambular $\mathrm{e}$ 
nenhum apresentou claudicação ou alterações locais no dígito que indicassem a ocorrência de laminite. Contudo, a ausência de sintomas não pode ser tomada como demonstração de que não se desenvolveram lesões no tecido laminar, uma vez que o exame foi realizado 14 horas após o início das lesões no intestino, período considerado insuficiente para se observar manifestação dos sintomas de laminite. Quando a enfermidade ocorre secundariamente ao abdome agudo, os sintomas são usualmente observados entre 24 e 72 horas do início dos distúrbios digestivos (White, 1990b); se for produzida experimentalmente pelo modelo de sobrecarga por carbohidratos, os sintomas surgem, em média, após 40 horas (Garner et al., 1975). No pós-operatório os animais foram medicados com butorfanol que, apesar de ser mais eficiente no controle da dor visceral (Kalpravidh et al., 1984) e sua última aplicação ter sido realizada aproximadamente quatro horas antes do exame dos dígitos, produziu analgesia a qual pode ter interferido na manifestação clínica da laminite.

Os escores de lesão no tecido laminar (Tab. 2) foram maiores $(\mathrm{P}<0,05)$ nos eqüinos dos grupos $\mathrm{T}$ e NT do que nos do grupo-controle (sem lesões). As lesões observadas nos animais dos grupos T e NT foram semelhantes.

Tabela 2. Escore médio da lesão no tecido laminar dos membros torácicos de eqüinos segundo os tratamentos

\begin{tabular}{|c|c|c|c|c|c|}
\hline \multicolumn{2}{|c|}{ Grupo-controle } & \multicolumn{2}{|c|}{ Grupo tratado } & \multicolumn{2}{|c|}{ Grupo não tratado } \\
\hline Eqüino & Escore & Eqüino & Escore & Eqüino & Escore \\
\hline 2 & 0 & 3 & 0 & 1 & 0,25 \\
\hline 4 & 0 & 5 & 0,5 & 6 & 1 \\
\hline \multirow[t]{4}{*}{12} & 0 & 8 & 1 & 7 & 0,5 \\
\hline & & 9 & 0,5 & 10 & 0,5 \\
\hline & & 13 & 0 & 11 & 1 \\
\hline & & 15 & 0,5 & 14 & 0 \\
\hline Média & $0 \mathrm{a}$ & & $0,14 \mathrm{~b}$ & & $0,54 \mathrm{~b}$ \\
\hline
\end{tabular}

Médias seguidas por letras iguais são equivalentes $(\mathrm{P}>0,05)$.

Ao exame histológico verificou-se presença de lesão discreta nas lâminas epidérmicas em nove dos animais submetidos à isquemia e reperfusão $(75 \%)$ (Fig. 1 e 2). Essa elevada freqüência chama a atenção, pois no presente estudo as lesões produzidas no intestino foram semelhantes àquelas descritas em pacientes portadores de abdome agudo de ocorrência natural (Meschter et al., 1986). Nestes, a incidência de laminite tem sido de aproximadamente 25\% (Cohen et al., 1994). Entretanto, a literatura consultada não menciona estudos sobre a histologia do tecido laminar durante a fase prodrômica da laminite, o que faz supor que a ocorrência de lesão nesse tecido, associada a episódios de abdome agudo, seja freqüente, mas de intensidade insuficiente para produzir manifestação clínica, na maioria dos casos. Segundo a correlação entre o grau de lesão tecidual e a intensidade dos sintomas estimada por Pollitt (1996) na laminite, é esperado o aparecimento de sintomas clínicos apenas quando as lesões teciduais correspondem a escores acima de 1 (leve), o que não foi verificado nos animais estudados. Como o intervalo entre o início das lesões no intestino e a colheita das amostras foi de apenas 14 horas, e que segundo Allen e Tyler (1990) a fase prodrômica da laminite tem duração de 24 a 48 horas, pode-se considerar que se o pós-operatório fosse mais longo, a possibilidade de verificar sua manifestação clínica seria maior.

Eyre et al. (1979), ao realizarem estudos in vitro, mostraram que os glicocorticóides potencializam a vasoconstrição periférica produzida pelas catecolaminas e serotonina nas artérias e veias digitais, o que poderia agravar a isquemia que ocorre no tecido laminar durante a laminite. Além disso, acredita-se que os glicocorticóides podem inibir a queratogênese (May, 1992). Esses achados motivaram o abandono da terapia com glicocorticóides na laminite e o seu emprego passou a ser contra-indicado para essa enfermidade (Baxter, 1994), mesmo com a inexistência de estudos controlados que avaliassem sua eficácia ou possíveis efeitos colaterais no cório decorrentes da sua utilização. 


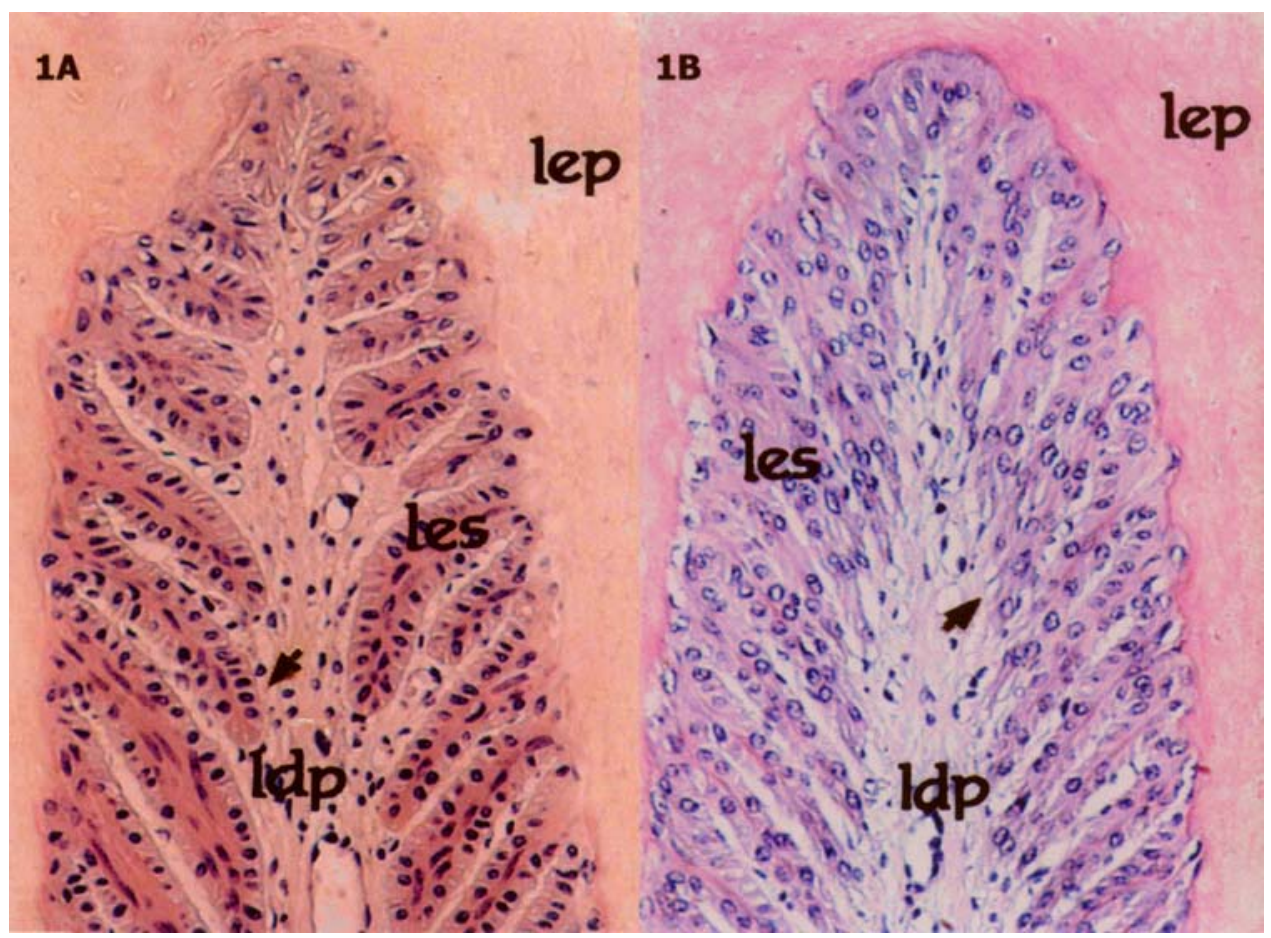

Figura 1. Tecido laminar de eqüino na base das lâminas epidérmicas primárias (LEP). 1A: tecido normal (eqüino 12). Formato arredondado da extremidade das lâminas epidérmicas secundárias (LES) (seta). HE. 268x. 1B: tecido laminar de eqüino submetido a isquemia e reperfusão intestinal apresentando lesão correspondente ao escore 1 (eqüino 6, membro torácico esquerdo). Estreitamento e individualização indefinida das LES (seta). HE. 268x. Lâmina dérmica primária (LDP).

Pass et al. (1998), em estudos in vitro, concluíram que alterações no metabolismo da glicose no tecido laminar produzem lesões semelhantes àquelas descritas na laminite e postularam que elas poderiam constituir um mecanismo adicional pelo qual os glicocorticóides desencadeariam essa enfermidade. French et al. (2000), ao estudarem os efeitos da triamcinolona no eqüino, determinaram que ela produz alterações dosedependentes no metabolismo da glicose, que persistem por até oito dias, e concluíram que esses achados reforçam a hipótese formulada por Pass et al. (1998). Independente das considerações anteriores, o grau de lesão observado no tecido laminar foi equivalente entre os grupos T e NT, possibilitando concluir que as lesões não foram produzidas ou agravadas pelo tratamento, provavelmente porque o SSH possui ação curta (May, 1992), além de ter sido administrado em dose única. Apesar de ser bem conhecida a ocorrência de efeitos colaterais após a administração de glicocorticóides, considera-se que eles resultam de sua utilização por períodos prolongados. Quando são de ação curta e dados em dose única, à semelhança do que foi realizado no presente estudo, mesmo em alta dosagem, não se observam efeitos colaterais relevantes (Goldfien, 1994; Behrend e Kemppainen, 1997). Até o presente, as tentativas de induzir experimentalmente a laminite pela administração de glicocorticóides não foram bem sucedidas (Johnson et al., 2002). Além disso, durante muito tempo, glicocorticóides foram utilizados no tratamento da laminite. Segundo Colles e Jeffcott (1977), seu efeito é considerado eficiente na fase de desenvolvimento da enfermidade. A metodologia utilizada possibilitou apenas a avaliação das lesões presentes no tecido laminar após aproximadamente 13 horas da administração do SSH. Entretanto, como a ação do SSH é curta, provavelmente no momento da colheita das amostras seu efeito máximo no tecido laminar já havia sido produzido, sendo pouco provável que o agravamento das lesões tenha sido decorrente de sua ação. 


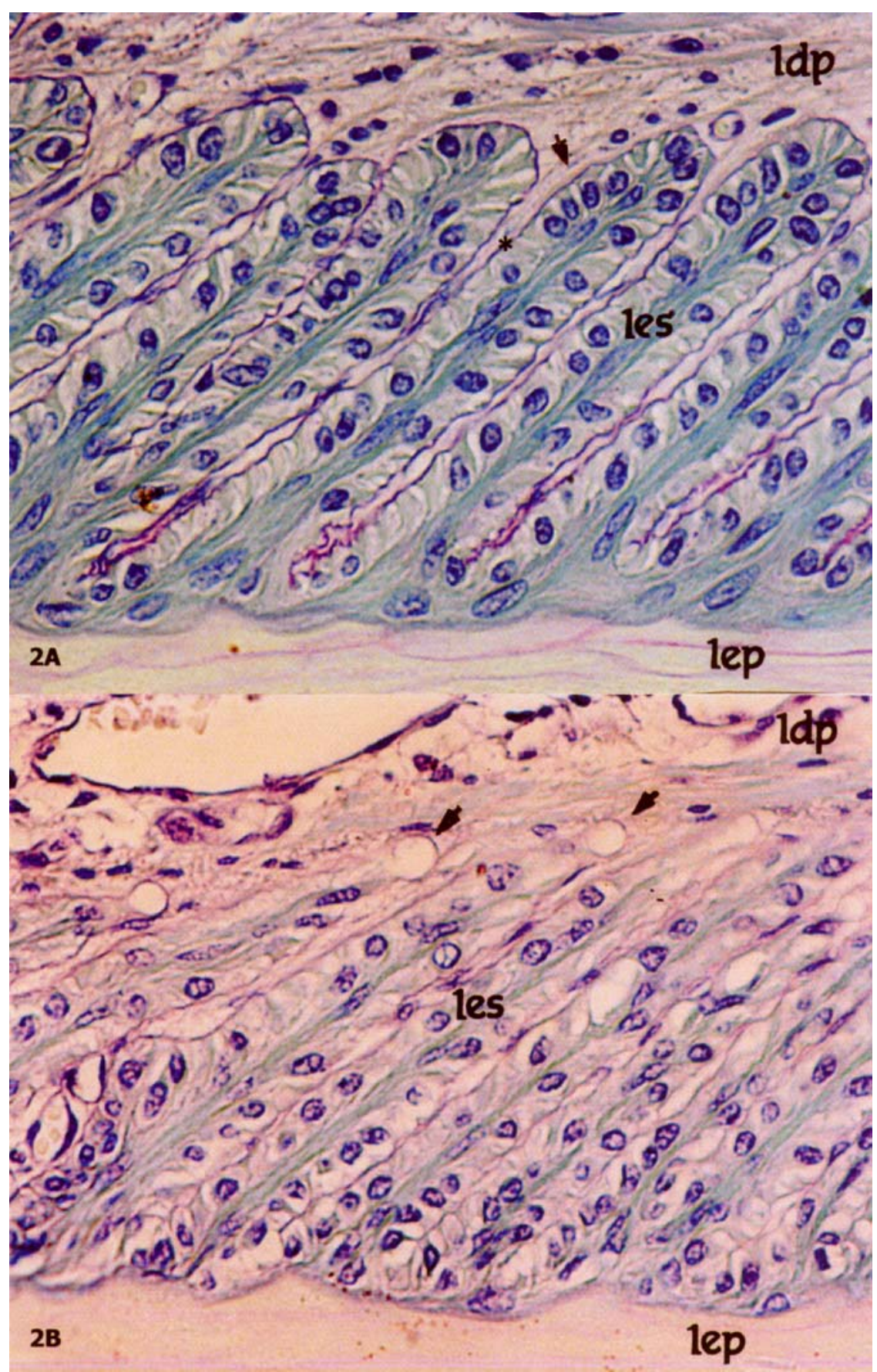

Figura 2. Tecido laminar de eqüino da base das lâminas epidérmicas primárias (LEP). 2A: tecido normal (eqüino 12). Células basais das lâminas epidérmicas secundárias (LES) justapostas à membrana basal (seta). O asterisco identifica a membrana basal. PAS. 777x. 2B: tecido laminar de eqüino submetido a isquemia e reperfusão intestinal apresentando lesão correspondente ao escore 1 (eqüino 6 , membro torácico esquerdo). Contorno das LES de difícil visualização e separação entre as células basais e a membrana basal em sua extremidade (setas). PAS. 777x. Lâmina dérmica primária (LDP). 
Os resultados indicam que o tratamento empregado não agravou as lesões produzidas no tecido laminar. Com base na hipótese de que o desencadeamento da laminite envolve a ativação excessiva de metaloproteinases (MTPs) que degradam a membrana basal das lâminas epidérmicas secundárias (Pollitt, 1996; Mungall et al., 2001), pode-se considerar até mesmo a possibilidade de que o SSH tenha produzido efeitos benéficos sobre o tecido laminar dos eqüinos do grupo $T$, uma vez que os glicocorticóides reduzem a produção do fator de necrose tumoral $\alpha$ e das interleucinas $1 \alpha$ e $1 \beta$ (Lew et al., 1988), citocinas que, segundo Pollitt (1996), podem induzir a ativação das MTPs na laminite. Caron et al. (1996) demonstraram que o efeito da interleucina $1 \beta$ no estímulo à produção de MTPs no eqüino pode ser bloqueado pelos glicocorticóides, o que pode explicar sua eficiência, no tratamento, relatada até a década de 70, nas fases iniciais da laminite (Colles e Jeffcott, 1977).

Com base nos resultados, conclui-se que a ocorrência de efeitos indesejáveis no cório secundários à IR no jejuno não foi agravada pelo tratamento com $\mathrm{SSH}$, o que possibilita sua utilização na rotina para o tratamento de eqüinos portadores de abdome agudo, sob condições semelhantes às produzidas no presente estudo.

\section{REFERÊNCIAS BIBLIOGRÁFICAS}

ALLEN, D.; TYLER, D.A. Pathophysiology of acute abdominal disease. In: WHITE, N.A. (Ed.). The equine acute abdomen. Philadelphia: Lea \& Febiger, 1990. p.65-88.

BAXTER, G.M. Acute laminitis. Vet. Clin. North Am.: Equine Pract., v.10, p.627-642, 1994.

BEHREND, E.N.; KEMPPAINEN, R.J. Glucocorticoid therapy: pharmacology, indications, and complications. Vet. Clin. North Am.: Small Anim. Pract., v.27, p.187-213, 1997.

CARON, J.P.; TARDIF, G.; MARTELPELLETIER, J. et al. Modulation of matrix metalloprotease 13 (collagenase 3) gene expression in equine chondrocytes by interleukin 1 and corticosteroids. Am. J. Vet. Res., v.57, p.1631-1634, 1996.
COHEN, N.D.; PARSON, E.M.; SEAHORN, T.L. et al. Prevalence and factors associated with development of laminitis in horses with duodenitis/proximal jejunitis: 33 cases. J. Am. Vet. Med. Assoc., v.204, p.250-254, 1994.

COLLES, C.M.; JEFFCOT, L.B. Laminitis in the horse. Vet. Rec., v.100, p.262-264, 1977.

DABAREINER, R.M; WHITE, N.A.; DONALDSON, L.L. et al. Evaluation of Carolina rinse as a treatment for ischemiareperfusion of the equine jejunum. Vet. Surg., v.27, p.521, 1998.

EYRE, P.; ELMES, P.J.; STRICKLAND, S. Corticosteroid-potentiated vascular responses of the equine digit: a possible pharmacologic basis for laminitis. Am. J. Vet. Res., v.40, p.135-138, 1979.

FORSYTH, S.F.; GUILFORD, W.G. Ischaemiareperfusion injury - a small animal perspective. Br. Vet. J., v.151, p.281 -298, 1995.

FRENCH, K.; POLLIT, C.C.; PASS, M.A. Pharmacokinetics and metabolic effects of triancinolone acetonide and their possible relationships to glucocorticoid-induced laminitis in horses. J. Vet. Pharmacol. Therap., v.23, p.287-292, 2000.

GAFFIN, S.L; GATHIRAM, P.; WELLS, M. et al. Effect of corticosteroid prophylaxis on lipopolysaccharide levels associated with intestinal ischemia in cats. Crit. Care Med., v.14, p.889-891, 1986.

GARNER, H.E.; COFFMAN, J.R.; HAHN, A.W. et al. Equine laminitis of alimentary origin: an experimental model. Am. J. Vet. Res., v.36, p.441-444, 1975.

GOLDFIEN, A. Corticosteróides supra-renais e antagonistas córtico-supra-renais. In: KARTZUNG, B.G. (Ed.). Farmacologia básica $e$ clínica. 5.ed. Rio de Janeiro: Guanabara Koogan, 1994. p.408-419.

HOOGMOED, L.V.; SNYDER, J. Adjunctive methods in equine gastrointestinal surgery. Vet. Clin. North Am.: Equine Pract., v.13, p.221-242, 1997.

HUBBELL, J.A.E. Monitoring. In: MUIR, W.W.; HUBBELL, J.A.E. (Eds.). Equine anaesthesia monitoring and emergency therapy. St. Louis: Mosby, 1991. p.153-159. 
JOHNSON, P.J.; SLIGHT, S.H.; GANJAM, V.K. et al. Glucocorticoids and laminitis in the horse. Vet. Clin. North Am.: Equine Pract., v.18, p.219-236, 2002.

KALPRAVIDH, M.; LUMB, W.V.; WHIGHT, M. et al. Effects of butorphanol, flunixin, levorphanol, morphine, and xylazine in ponies. Am. J. Vet. Res., v.45, p.217-223, 1984.

LEW, W.; OPPENHEIM, J.J.; MATSUSHIMA, $\mathrm{K}$. Analysis of the suppression of IL- $1 \alpha$ and IL$1 \beta$ production in human peripheral blood mononuclear adherent cells by a glucocorticoid hormone. J. Immunol., v.140, p.1895-1902, 1988.

LUNA, L.G. Manual of histologic staining methods of the Armed Forces Institute of Pathology. 3.ed. New York: McGraw Hill, 1968. 257p.

MAY, S.A. Anti-inflamatory agents. In: ROBINSON, N.E. (Ed.). Current therapy in equine medicine. 3.ed. Philadelphia: Saunders, 1992. p.14-16.

MESCHTER, C.L.; TYLER, D.E.; WHITE, N.A. et al. Histologic findings in the gastrointestinal tract of horses with colic. Am. J. Vet. Res., v.47, p.598-606, 1986.

MOORE, R.M.; ALLEN, D.; CLARK, E.S. Pathophysiology of acute laminitis. Equine Pract., v.13, p.29-32, 1991.
MOORE, R.M.; MUIR, W.W.; GRANGER, D.N. Mechanisms of gastrointestinal ischemiareperfusion injury and therapeutic interventions: a review and its implications in the horse. $J$. Vet. Int. Med., v.9, p.115-132, 1995.

MUNGALL, B.A.; KYAW-TANNER, M.; POLLIT, C.C. In vitro evidence for a bacterial pathogenesis of equine laminitis. Vet. Microbiol., v.79, p.209-223, 2001.

PASS, M.A.; POLLITT, S.; POLLITT, C.C. Decreased glucose metabolism causes separation of lamellae in vitro: a trigger for laminitis? Equine Vet. J., v.26, Suppl., p.133-138, 1998.

POLLITT, C.C. Basement membrane pathology: a feature of acute equine laminitis. Equine Vet. $J .$, v.28, p.38-46, 1996.

SAMPAIO, I.B.M. Estatística aplicada à experimentação animal. Belo Horizonte: FEPMVZ, 1998. 221p.

SLATER, M.R.; HOOD, D.M.; CARTER, G.K. Descriptive epidemiological study of the equine laminitis. Equine Vet. J., v.27, p.364-367, 1995.

WHITE, N.A. Epidemiology and etiology of colic. In: WHITE, N.A. (Ed.). The equine acute abdomen. Philadelphia: Lea \& Febiger, 1990a. p.49-64.

WHITE, N.A. Intensive care, monitoring, and complications of acute abdominal disease. In: WHITE, N.A. (Ed.). The equine acute abdomen. Philadelphia: Lea \& Febiger, 1990b. p.309-335. 